\title{
School Performance and Technology: The Importance of ICT Skills for Chilean Student's Learning
}

\author{
Carlos Rodríguez Garcés \\ ORCID: 0000-0002-9346-0780 • ResearcherID: T-6352-2017 \\ Johana Muñoz Soto \\ ORCID: 0ooo-0003-1858-7500 \\ Universidad del Bío-Bío, CIDCIE Research Center, Chillán
}

Received 20 November 2017 Revised 30 November 2017 • Accepted 4 December 2017

\begin{abstract}
The article analyzes the school performance of Chilean secondary school students in the areas of Language, Mathematics and ICT using the database of the SIMCE 2013 Survey. It also measures the contribution of technologies to the level of school performance, analyzing their impact, compared to other components of the student's socio-family profile. For this purpose, descriptive-correlational and Logistic Regression analyzes are performed. It is found that levels of school achievement are poor and are deeply segmented according to the student's family income level. Although components of technological profile have an impact in this respect, the economic and cultural attributes are the structuring components of performance.
\end{abstract}

Keywords: school performance, level of achievement, standardized tests, ICT skills, ICT experience, lag.

\section{Introduction}

The educational system is a framework of didactic and disciplinary levels and processes in which various actors intervene in order to learners acquire knowledge and also quality and relevant skills in the different areas of the school curriculum. Since the creation of the Education Quality Measurement System (SIMCE) in 1988 in Chile, deficits and segmented achievement levels of the school population have been informed (Aguirre, Castro \& Adasme, 2009; Mora, 2010).

Learning is a complex social phenomenon on which a set of personal, socio-family and institutional factors of varying magnitude and nature intervene in continuous interaction. When explaining school performance, cultural and family economic capital attributes are predictable factors, which have a significantly higher incidence than that attributed to the school (Lozano, 2000; Brunner \& Elacqua, 2005; Navarro, 2003). The educational institution evidences difficulties to incorporate added value in the educational process, particularly in the poorest, making them responsible for the deepening of the learning gaps (Matear, 2007; Gisbert \& Esteve, 2011; Tejedor \& García-Valcárcel, 2006).

(C) Authors. Terms and conditions of Creative Commons Attribution 4.0 International (CC BY 4.0) apply. Correspondence: Carlos Rodríguez Garcés, Universidad del Bío-Bío, CIDCIE Research Center, Casilla 447-Chillán, Chile. E-mail: carlosro@ubiobio.cl. Tel: +56422463618. 
School success, is therefore strongly linked to socio-family coordinates, conditioning performance, educational expectations and attitude towards student's learning based on their social origin. Parents transfer attitudes and expectations to their children, which vary according to socioeconomic status (Arnold \& Doctoroff, 2003); Mothers with a lower level of schooling would be less rigorous and selective regarding educational material, showing less concern about what their children are learning compared to those who are more educated (Piacente \& Tittarelli, 2009). Similarly, parents of lower socioeconomic status tend to have lower levels of schooling and cultural capital, a situation that would directly influence their children's school performance (OECD, 2010; IEA, 2008; Marks, Cresswell \& Ainley, 2006). There is even a significant relationship between school performance in literacy and the family level of income (Magnuson, 2007).

In poor households, there would be less availability of quantity and quality cultural artifacts. For example, the reduced presence of books restricts reading habits, language comprehension and vocabulary management (Bus, Van Ijzendoorn \& Pellegrini, 1995). The sociocultural level not only influences the availability of educational potential material existing at home, but also determines the relevance and quality of the experience with them.

On the other hand, in the context of learning, especially in areas of socio-educational vulnerability, Information and Communication Technologies (ICT) can be an important tool to guarantee quality, relevance and equity in the levels of educational achievement. ICTs have the potential to democratize access to knowledge and to develop meaningful learning experiences using the educational material available in them. The new generations demand a greater use of technologies to achieve school success (Pedró, 2006), since the mastering of them would influence the academic performance, in strategic curricular sectors such as Language and Mathematics (Formichella, Alderete \& Meglio, 2009; Spiezia, 2011; Cristia, Ibarraran, Cueto, Santiago \& Severin, 2012; Torres \& Padilla, 2015). The Internet, for example, based exclusively on written text and used in a non-sporadic way, would improve reading results (Jackson et al., 2006; Jackson, von Eye, Witt, Zhao \& Fitzgerald, 2011).

Although ICTs have an important potential for school learning, they are only tools that accompany the educational process, so the results will depend on the use that is being made of them (McFarlane, Sparrowhawk \& Heald, 2002). The availability, knowledge and use, condition the quality of the educational experience. When, for example, the computer is used mainly for communicative and non-academic leisure activities, its use would not have positive effects on school performance (Montero \& Nahuelpán, 2010). Also, according to authors like Schofield, Demont and Webber (2005), Hollingworth, Mansaray, Allen and Rose (2011), Hargittai (2010), in poor economic contexts, ICT penetration is more limited and less intensive use is made of them.

The school system shows important difficulties to install ICT skills and abilities in its students, especially when compensating for the weaknesses of the technologically most neglected sectors. ICTs find serious barriers to penetrate the education system and the classroom's black box. Beyond the declaratory level and strong social desirability of the pedagogical discourse, with its politically correct imprint of modernity that makes the use of ICT a recurrent linguistic expression to define the task, the truth is that pedagogical strategies are rather conservative and do a low use of technologies. It is not that ICT is outside the teaching profession, but its use is more reserved to the administrative management of the curriculum than to the development and implementation of it.

The scarce and rudimentary use of ICT is one of the main weaknesses to be overcome by pedagogical action, especially when several research findings inform its importance in the installation of higher levels of educational achievement. If ICTs were used as part of the classroom experience, the impact on student learning would be greater (Condie, Munro, Seagraves \& Kenesson, 2007; Claro, 2010). The use of ICT in school, along with promoting reasoning (Cox, 
2003), reinforces the pedagogical role by allowing bi-directional interactions during the learning process (Gómez \& Macedo, 2010).

In short, the quality of learning would be conditioned upon a set of socio-cultural and technological factors distributed with little homogeneity within the Chilean school population. In this sense, based on socioeconomic segmentation, this article comparatively analyzes the quality of learning informed by SIMCE standardized tests in the curricular areas of Language, Mathematics and Technology for the second year of secondary education or high school. Specifically, it emphasizes the contribution of ICT skills in school performance, analyzing its predictive capacity and incidence in comparison with other socio-cultural profile components.

\section{Methodology}

The databases of the Education Quality Measurement System (SIMCE) tests of Mathematics, Language and ICT skills for Learning (SIMCE-TIC) applied by Chile's Ministry of Education in 2013 to second year high school students are used in this article. These databases are available for academic research since the end of 2014.

The Mathematics and Language SIMCE Tests evaluate the achieved learning in these subjects based on the standard established in the fundamental objectives and obligatory minimum contents of the current national curricular framework. School performance is expressed through score and level of achievement:

- Adequate Learning Level: the student has demonstrated that he/she has acquired the basic knowledge and skills stipulated in the curriculum according to his/her grade level. In the case of mathematics implies that the student obtains a score equal to or greater than 319, and for language 295 or more.

- Elementary Learning Level: students demonstrate partial knowledge and skills according to their grade level. In the Language test implies a score between 250 and 295 points, and between 252 and 319 points for mathematics.

- Insufficient Learning Level: students in this level have not acquired the elementary knowledge and skills stipulated in the national curriculum. In the case of mathematics, students in this level are under 252 points and under 250 points in the case of language.

On the other hand, SIMCE- ICT has the purpose of determining de development of ICT skills for educational learning and also of knowing the personal factors and context related with the achieved technological appropriation level through the application of two context surveys, one for parents and another for the implied students. Both surveys, under reserved and confidential conditions, aim to find out socio-familiar attributes, attitude towards ICT, as well as availability, knowledge and use made of technologies at home and school.

SIMCE-ICT evaluates face-to-face the student's competencies in problem and task solving in the school context through the use of basic computer applications and internet tools. This test is carried out in front of a computer with an ad hoc computer application that emulates a virtual environment on which the student receives instructions to solve problems associated with a curricular transverse unit. At the disaggregated level it measures a total of 12 skills distributed in three dimensions: Information, Communication, and Ethics and Social Impact.

The Information dimension evaluates competencies related to the search, selection, evaluation and organization of pertinent and necessary information at the user-student level, as well as the capacity he/ she manifests to integrate, understand, analyze and represent those findings (Enlaces, 2013). In the Communication dimension, the student's ability to transmit information through technological means is evaluated. Specifically, it explores and quantifies the 
capacity to recognize the components of the information to be communicated, identify the means to transmit it and select the most pertinent one based on the context. Finally, the area of Ethics and Social Impact dimensions the capacity to recognize and reflect on ethical dilemmas that technologies present in their relationship with personal and others lives and society as a whole. At the disaggregated level, it explores privacy protection, network security and responsible use of ICT.

From these skills, three levels of achievement are elaborated which allow to classify the performance of each student according to the obtained score:

- Initial Level: the student interprets simple information and is able to make a basic and rudimentary use of ICT, obtaining a score equal to or less than 245 points.

- Intermediate level: the student makes a basic functional use of the simplest digital tools, solving concrete problems. The score varies between 246 and 335 points.

- Advanced Level: they show an advanced functional use of more complex ICTs, which allows them to solve problems flexibly and efficiently. The score that the student must obtain at this level is 336 or more points.

Unlike the census character of the Mathematics and Language Test, the SIMCE-ICT is applied to a representative sample of the students. National and region representative stratified random sampling is used for data compilation at a student and educational unit level. Only students participating in each of the tests have been considered for this analysis purpose due to this procedural difference, using the SIMCE- ICT compilation as basis.

This methodological decision allows homogenizing the databases and being in accordance with the research purposes, despite the eventual loss of information. This structure is composed of 9,781 students, distributed in a total of 490 establishments, mostly belonging to subsidized private institutions (45.7\%), urban sectors (94.6\%), with a relatively greater presence of men (52.1\%).

For the research purposes that guide this article, an analysis in two levels was made using the information of the Mathematics, Language and SIMCE-ICT tests compacted in one base.

In the first instance, a descriptive-correlational analysis is carried out characterizing the behavior registered by the levels of achievement in the different tests, controlled by socioeconomic level which, according to the consulted literature, structurally conditions the academic performance of the student. Secondly, in order to give greater depth to the preliminary analyzes, the deficient level of educational achievement in the Mathematics and Language tests is modeled based on the possible incidence of the student's set of technological, educational and socio-cultural factors, modeled by a binomial logistic regression analysis.

Standardized indexes of Home Technological Equipment, ICT Experience and SIMCEICT performance were constructed for the configuration of the technological profile components. For analysis purposes, indexes are later made ordinal:

- ICT experience: referred to the time the student has been using a computer, expressed in years.

- Technological Equipment: it is measured by the presence / absence of six artifacts and the variety and availability of digital devices at home. Standardized index that is categorized for analysis purposes in three levels; Low (<0.25), Medium (0.25-0.50) and High (>0.50).

- SIMCE-ICT performance: level of achievement based on the standard reached by the student in the SIMCE test of ICT skills for learning. The obtained score is dichotomized for analysis purposes, distinguishing the Initial (<245) and Elementary-Advanced (> 246) levels. 
For socio-cultural factors, the socio-economic stratum was used. This variable is expressed in five levels based on the classification provided by the Ministry of Education, and it was supplemented with the level of maternal schooling and the number of books existing in the household, these variables were used as proxy of the socio-cultural level of the student's family. In particular, the number of books can be even considered as an efficient variable to estimate the family socioeconomic level (Schütz, Ursprung \& Wöbman, 2008).

Finally, regarding the educational profile components, besides the well-known school performance in Mathematics and Language tests, the repetition condition is recorded.

\section{Analysis}

The SIMCE test measures the quality and equity in learning of Chilean students through various standardized tests, designed based on the fundamental objectives and minimum obligatory contents of the educational curriculum established for the student's grade level (MINEDUC, 2009).

Graph 1. Low level of achievement according to GSE (\%)

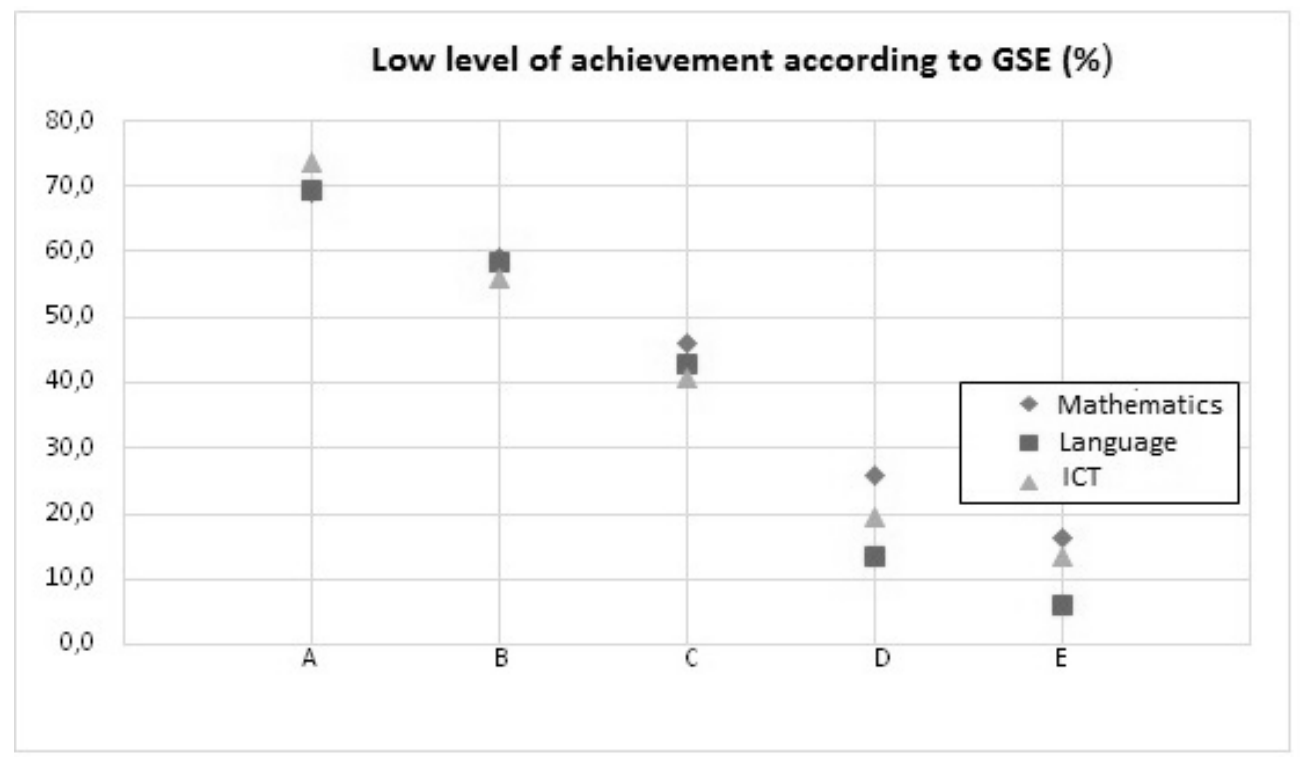

Note: GSE= Socioeconomic Group; A= Low GSE; B= Low to Medium GSE; C= Medium GSE; $\mathrm{D}=$ Medium- high GSE; E= High GSE.

Source: SIMCE, 2013. Authors own elaboration.

Regarding this study, data report the low level of achievement attained in the three analyzed tests. Students obtained an average of $255.2 \pm 56.5$ points in language (Table 1) and only 26.7\% demonstrated adequate knowledge for their corresponding grade level, while $45.8 \%$ presented an insufficient level of achievement (Graph 1). That is, about one out of every two students will find it difficult to read and comprehensively understand different types of texts.

In the Mathematics test, similar results are observed. On average students present $268.95 \pm 68.87$ points (Table 1) and 41.3\% an insufficient level of achievement (Graph 1), registering little mastery and application of elementary procedures of arithmetic, algebra and geometry.

National educational system difficulties in granting quality education in the different areas of the curriculum are also verified when assessing the level of skills and competencies in the 
use of technologies for learning. In the SIMCE-ICT test, with an average score of $251.14 \pm 49.83$ (Table 1), only $2.8 \%$ register an advanced level of proficiency, while $43.5 \%$ are placed at an initial achievement level (Figure 1), which is considered insufficient for the student's grade level. Generally speaking, one out of every two students shows only a functional and rudimentary management of ICTs. Scarce use and knowledge that represents a handicap that violates the student's educational performance since the technological tools are not only necessary to learn in the current school context, but also throughout life (Morrisey, 2007).

Based on the socioeconomic profile of the students, deep segmentation is added to these low levels of achievement. As parents' levels of family and educational income decline, scores on standardized tests decrease too, increasing the proportion of students who rank the lowest achievement levels. This learning gap is an expression of a fast process of socio-educational segmentation and a distinctive characteristic of a school system based on vouchers, parents' freedom of educational choice and of the little/low state intervention.

The school evidences difficulties to install quality learning. It fails to offset the deficiencies of an impoverished socio-cultural family context and even causes the existing gaps to expand. In mathematics, the probability of a low socioeconomic level student to be part of the lowest performance level is 11.5 times higher than that of a student of high socioeconomic status. In language and ICT, although less pronounced than in mathematics, the gaps are equally significant, reaching Ods Ratio of 4.2 and 5.5 respectively.

Table 1. Language and Mathematics Performance according to GSE and SIMCE-ICT Level of Achievement (average score and correlations)

\begin{tabular}{|c|c|c|c|c|c|c|}
\hline & & \multicolumn{3}{|c|}{ SIMCE-ICT level of Achievement } & \multirow[b]{2}{*}{ General } & \multirow[b]{2}{*}{$\mathrm{R}_{\mathrm{xy}}{ }^{1}$} \\
\hline & GSE & Initial & Intermediate & Advanced & & \\
\hline \multirow[t]{2}{*}{ 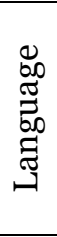 } & $\begin{array}{l}\text { - Low and Low to } \\
\text { Medium } \\
\text { - Medium } \\
\text { - High and Medium- } \\
\text { High }\end{array}$ & $\begin{array}{l}212,8 \pm 41,6 \\
218,5 \pm 43,7 \\
240,3 \pm 49,6\end{array}$ & $\begin{array}{l}267,5 \pm 47,7 \\
275,2 \pm 45,2 \\
293,9 \pm 43,8\end{array}$ & $\begin{array}{c}313,9 \pm 27,7 \\
320,8 \pm 23,8 \\
333,4 \pm 33,9\end{array}$ & $\begin{array}{l}230,9 \pm 50,8 \\
252,8 \pm 52,9 \\
287,9 \pm 49,9\end{array}$ & $\begin{array}{l}0,61^{* *} \\
0,63^{* *} \\
0,56^{* *}\end{array}$ \\
\hline & General & $217,6 \pm 44,0$ & $281,8 \pm 46,6$ & $330,3 \pm 32,5$ & $255,2 \pm 56,5$ & $0,68 * *$ \\
\hline \multirow{2}{*}{ 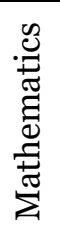 } & $\begin{array}{l}\text { - Low and Low to } \\
\text { Medium } \\
\text { - Medium } \\
\text { - High and Medium- } \\
\text { High }\end{array}$ & $\begin{array}{l}212,2 \pm 48,6 \\
225,4 \pm 52,3 \\
275,2 \pm 60,4\end{array}$ & $\begin{array}{l}268,3 \pm 51,9 \\
285,1 \pm 50,5 \\
329,8 \pm 47,4\end{array}$ & $\begin{array}{c}333,1 \pm 41,5 \\
337,9 \pm 39,2 \\
367,1 \pm 35,6\end{array}$ & $\begin{array}{l}230,9 \pm 56,5 \\
261,6 \pm 59,7 \\
323,5 \pm 54,3\end{array}$ & $\begin{array}{l}0,58^{* *} \\
0,60^{* *} \\
0,52^{* *}\end{array}$ \\
\hline & General & $223,3 \pm 54,8$ & $301,1 \pm 56,2$ & $360,4 \pm 38,5$ & $268,9 \pm 68,9$ & $0,68^{* *}$ \\
\hline
\end{tabular}

Added to the differential level of appropriation of the curriculum in the mathematics and language sectors of Chilean students, are the insufficient and rudimentary ICT skills for learning, establishing even that those who register low performance in these areas of the curriculum also demonstrate low level in ICT skills.

In fact, as ICT performance levels improve, scores on standardized tests also improve. Those who demonstrate an advanced level in the management of technologies, registered a score 51.8\% and 61.4\% higher in Language and Mathematics tests, compared to those who have initial performance in SIMCE-ICT. The analysis shows that these gaps become more significant when contrasted by socioeconomic group, establishing in the first instance, that educational 
achievements in these areas of the curriculum are strongly conditioned by socio-family coordinates.

Despite the ICT competencies correlation to the Mathematics and Language performance, they would not be a determinant factor in the educational achievement; consequently all the association found must be cautiously analyzed when establishing a cause and effect bond for two fundamental reasons: First and consistent with the findings reported by OECD (2010), Aguirre, Castro and Adasme (2009), family social and cultural capital would be the main structurer of the differential school performance found in the different tests. Second, the measured digital literacy levels are structured and dimensioned based on a text comprehension process, so it is likely expected that students who demonstrate skills using traditional methods, also achieve competencies applying a new evaluative context.

In fact, the research findings that seek to causally relate ICT competences with academic performance are controversial and of dissimilar results. However, at the immediate and general level, our data report moderately high and statistically significant correlations (Table 1), both for mathematics [ $\mathrm{rxy}=0.68 ; \mathrm{P}<0.01]$ as for Language $[\mathrm{rxy}=0.68 ; \mathrm{P}<0.01]$. This implies that, in the context of bivariate analysis, the variability explained in the performance achieved in these curricular sectors is due $46 \%$ average to the performance obtained in SIMCE-ICT. These correlations remain constant, in terms of orientation and intensity, even when controlling by socioeconomic group, being only slightly lower in the High and Medium-High GSE level, both for Mathematics [rxy $=0.52 ; \mathrm{P}<0.01]$ and for Language [ $\mathrm{rxy}=0.56 ; \mathrm{P}<0.01]$.

In order to calculate the incidence of information and communication technologies, especially the level of SIMCE-ICT in school performance from a context of complexity, four multivariate logistic regression models were developed, where a set of technological profile variables of the students' cultural and socioeconomic capital are included. For each of the Language and Mathematics tests, two models are built. The first considers all the independent or predictive variables, while the second, which is more restricted, only considers the technological profile factors.

Table 2. Lag of the educational performance in language and mathematics SIMCE tests

\begin{tabular}{|c|c|c|c|c|c|c|}
\hline & \multicolumn{3}{|c|}{ Language } & \multicolumn{3}{|c|}{ Mathematics } \\
\hline & $\%$ & $\operatorname{Exp}(\beta)^{1}$ & $\operatorname{Exp}(\beta)^{2}$ & $\%$ & $\operatorname{Exp}(\beta)^{1}$ & $\operatorname{Exp}(\beta)^{2}$ \\
\hline $\begin{array}{l}\text { ICTs level of achievement: } \\
\text { - Initial } \\
\text { - Intermediate-Advanced }\end{array}$ & $\begin{array}{l}76,7 \\
22,1 \\
\end{array}$ & $\begin{array}{c}\text { Ref. } \\
0,12^{* *}\end{array}$ & $\begin{array}{c}\text { Ref. } \\
0,15^{* *}\end{array}$ & $\begin{array}{l}71,0 \\
18,5 \\
\end{array}$ & $\begin{array}{c}\text { Ref. } \\
0,13^{* *}\end{array}$ & $\begin{array}{c}\text { Ref. } \\
0,17^{* *}\end{array}$ \\
\hline $\begin{array}{l}\text { ICT Equipment at home: } \\
\text { - Low } \\
\text { - Medium } \\
\text { - High }\end{array}$ & $\begin{array}{r}51,9 \\
33,0 \\
21,1\end{array}$ & $\begin{array}{l}\text { Ref. } \\
0,75^{* *} \\
0,52^{* *}\end{array}$ & $\begin{array}{l}\text { Ref. } \\
1,09 \\
1,16\end{array}$ & $\begin{array}{l}49,5 \\
26,0 \\
12,9\end{array}$ & $\begin{array}{c}\text { Ref. } \\
0,56^{* *} \\
0,30^{* *}\end{array}$ & $\begin{array}{l}\text { Ref. } \\
1,08 \\
1,42\end{array}$ \\
\hline $\begin{array}{l}\text { ICT Experience: } \\
\text { - Low } \\
\text { - Medium } \\
\text { - High } \\
\end{array}$ & $\begin{array}{l}74,5 \\
56,9 \\
34,7\end{array}$ & $\begin{array}{l}\text { Ref. } \\
0,64^{* *} \\
0,41^{* *}\end{array}$ & $\begin{array}{c}\text { Ref. } \\
0,67^{* *} \\
0,52^{* *}\end{array}$ & $\begin{array}{l}73,5 \\
53,7 \\
29,0 \\
\end{array}$ & $\begin{array}{c}\text { Ref. } \\
0,56^{* *} \\
0,34^{* *}\end{array}$ & $\begin{array}{l}\text { Ref. } \\
0,54^{* *} \\
0,44^{* *}\end{array}$ \\
\hline $\begin{array}{l}\text { Sex: } \\
\text { - Male } \\
\text { - Female }\end{array}$ & $\begin{array}{l}49,2 \\
42,1\end{array}$ & & $\begin{array}{c}\text { Ref. } \\
0,69^{* *}\end{array}$ & $\begin{array}{l}38,0 \\
44,9 \\
\end{array}$ & & $\begin{array}{l}\text { o, } 55^{* *} \\
\text { Ref. }\end{array}$ \\
\hline $\begin{array}{l}\text { Has repetead: } \\
\text { - Yes } \\
\text { - No }\end{array}$ & $\begin{array}{l}67,9 \\
41,6\end{array}$ & & $\begin{array}{l}\text { Ref. } \\
0,61^{* *}\end{array}$ & $\begin{array}{l}65,8 \\
36,7\end{array}$ & & $\begin{array}{l}\text { Ref. } \\
0,47^{* * *}\end{array}$ \\
\hline
\end{tabular}


Garcés \& Soto - School Performance and Technology: The Importance of ICT ...

\begin{tabular}{|l|c|c|c|c|c|c|}
\hline GSE: & & & & & & \\
- Low & 69,2 & & Ref. & 69,5 & & Ref. \\
- Low to Medium & 59,0 & & 0,91 & 58,3 & & 0,79 \\
- Medium & 46,1 & & 0,76 & 42,9 & & $0,59^{* *}$ \\
- Medim High & 25,8 & & $0,52^{* *}$ & 13,3 & & $0,16^{* *}$ \\
- High & 16,3 & & $0,32^{* *}$ & 6,0 & & $0,06^{* *}$ \\
\hline Mother's Educational level: & & & & & & \\
- Up to 8 years & 66,2 & & Ref. & 66,4 & & Ref. \\
- 9-12 years & 45,3 & & 1,03 & 41,1 & & 1,18 \\
- More than 12 years & 22,6 & & 0,91 & 14,2 & & 1,20 \\
\hline Books at home: & & & & & & \\
- Less than 10 & 63,1 & & Ref. & 61,6 & & Ref. \\
- Between 11-30 & 49,3 & & o,90 & 43,6 & & O,73 \\
- More than 30 & 31,9 & & 0,68** & 26,6 & & $0,66^{* *}$ \\
\hline
\end{tabular}

1= Model involving exclusively technological profile variables; $2=$ Model involving technological profile and socio family, cultural and educational variables.

$*^{*}=$ Level of significance at 0,$01 ;{ }^{*}=$ Level of significance at 0,05

Source: Authors own elaboration based on SIMCE, 2013.

Concerning the ICT equipment at home, the simple proportion analysis indicates that students with a lag in their school performance belong to the most technologically precarious segments. Of students from low digital endowments homes, one in two shows low performance in both Language (51.9\%) and Mathematics (49.5\%). Significantly lower proportions are evidenced when there is a high endowed household, especially in Mathematics (12.9\%). The regression analysis, on the other hand, reports that by having a Low ICT Equipment Level at home (Ref.), the probability of registering a low performance at a Medium Level is reduced by $25 \%$ in Language $[\operatorname{EXP}(\beta)=0.75 ; \mathrm{P}<0.01]$ and $44 \%$ in Mathematics $[\operatorname{EXP}(\beta)=0.56 ; \mathrm{P}<0.01]$. This reduction of probability is more pronounced when compared to the High ICT Equipment segment, especially for Mathematics [EXP $(\beta)=0.30 ; \mathrm{P}<0.01]$. However, the incidence of household ICT equipment in models that only include technological profile attributes (Model 1) becomes non-significant when incorporating the set of other variables. In a greater analytical complexity context, sociofamily factors would be more relevant. Students' cultural, educational and economic capital components are associated with school performance and with having digital tools in variety and quantity.

On the other hand, SIMCE-ICT experience of use and level of accomplishment register significant incidence regardless of the model used. Seniority in the exploration of the network is important when analyzing levels of educational achievement, both at the level of bivariate and regression correlations. Considering Low Experience (Ref.) as a reference, the probability of presenting low performance when having a Medium level, is $36 \%$ lower in Language $[\mathrm{EXP}(\beta)=$ $0.64 ; \mathrm{P}<0.01]$ and 44\% lower in Mathematics $[\operatorname{EXP}(\beta)=0.56 ; \mathrm{P}<0.01]$. The risk of falling into the lag zone is further reduced in a High experience level, both for Mathematics $[\mathrm{EXP}(\beta)=0.34$; $\mathrm{P}<0.01]$ as for Language $[\operatorname{EXP}(\beta)=0.41 ; \mathrm{P}<0.01]$. In the bivariate space, of those with little experience of use, a proportion close to $74 \%$ presents low school performance. This is reduced to $30 \%$ in the segment of greater time of use.

Finally and among the analyzed technological profile factors, the level of SIMCE-ICT domain would affect the school performance. It provides the most important indexes in the analyzed models, along with the socioeconomic configuration component. $71 \%$ of those with low technological proficiency have low performance in Mathematics, and increased cipher of $76.7 \%$ in the case of Language. This proportion is significantly lower when the student demonstrates greater digital competencies (22.1\% in Language and $\mathbf{1 8 . 5 \%}$ in Mathematics). These results are endorsed in the multivariate space, here it is observed that the probability of being in a situation of educational insufficiency when the students reach a SIMCE Intermediate / Advanced ICT level of 
achievement is significantly reduced in Mathematics $[\operatorname{EXP}(\beta)=0,13 ; \mathrm{P}<0.01]$ and in Language $[\operatorname{EXP}(\beta)=0.12 ; \mathrm{P}<0.01]$.

The availability of technology at home, especially the presence of the Internet, and the student's seniority as a user makes it possible for him/her to have a more extensive exploration and knowledge of the network without the restrictions of other places of access, articulate selflearning experiences and enrich educational processes for greater acquisition of educational competencies (Román \& Murillo, 2014; Condie, Munro, Seagraves \& Kenesson, 2007; Trucano, 2005). It is not surprising then, that in the carried out analysis a link between school performance and technological profile is established, either in its availability dimension, use experience or SIMCE-ICT competencies. However, this relationship is not linear causal, since both, the vectors that comprises the technological variables and the educational performance, are strongly conditioned by socioeconomic coordinates. In this context, the socio-cultural and economic attributes would be the incidental variables contaminating this relationship.

Although there is no consensus in this regard, research such as the one from Woessmann and Fuchs (2004) in the light of the PISA test results conclude that ICT's do not show a positive impact on the student's performance regardless the place of access and once the sociofamily and educational institution variables are controlled. On the contrary and in this same line of argument, the limited use of academic-informative purpose of ICT in the home is associated with low school performance. Thus, to own and use technology is not enough to improve school performance, it is also necessary a less rudimentary use of it that complements communicative leisure with academic and educative purpose. It has been shown that when there is a low ICT use for academic purposes, one in every two students' results is insufficient in the Language test (51\%), and similar results are shown in the Mathematics test (48\%).

A set of the student's cultural, educational and socioeconomic capital attributes are added to the previously mentioned technological factors to evaluate their incidence in the scores obtained in the tests of Language and Mathematics. Although sex does not constitute a structuring variable in school performance levels in standardized tests, differential behaviors are observed in its binomial expression. A greater proportion of men have low performance in Language (49.2\%) compared to women $(42.1 \%)$. In the Mathematics test, on the other hand, the performance of women is more deficient. Consistent results are observed in the regression models that attribute that being a woman is a protective factor for lagging in Language [EXP $(\beta)=0.69 ; \mathrm{P}<0.01$ ], whereas in mathematics it is the fact of being a male $[\mathrm{EXP}(\beta)=0.55 ; \mathrm{P}<0.01]$. In this vein, consulted literature reports small differences by gender in terms of cognitive abilities, but women would have a greater verbal fluency, better reading comprehension and spatial memory while men would succeed upon them in solving mathematical problems (Spelke, 2005, Belo, Ferreira \& Telang, 2010).

The repetition variable at the educational profile level is, as expected, a relevant risk factor for the student's academic performance, especially in Mathematics [EXP $(\beta)=0.47$; P $<0.01]$. In fact, deficient academic records condition educational trajectories. According to Cerón and Lara (2011), students who show repetition in their academic records have considerably lower scores than those who have not failed.

Finally, socio-cultural attributes show the highest incidences in the levels of performance in the standardized tests. Family socioeconomic stratum, parental educational level and the presence of texts at home have special relevance.

Students show low performance in Language (69.2\%) and Mathematics (69.5\%) when belonging to a Low- GSE, proportion that drops significantly in High- GSE. In this segment, only $6 \%$ is lagging in Mathematics and $16.3 \%$ in Language. Belonging to school segments with higher incomes (High and Medium-High) is a factor of protection against low level of achievement, especially in Mathematics [EXP $(\beta)=0.06$; $\mathrm{P}<0.01$ ]. Plenty of literature provides similar 
conclusions. For authors such as Santín (2003), Rodríguez (2014) and Tedesco (2000), family socioeconomic level is one of the most relevant factors when explaining learning outcomes, even greater than school.

Maternal educational level and the number of books at home, used as a proxy for family cultural capital, also affect in the same orientation in school performance, although their results differ depending on the model used. In the bivariate context, as the educational level of the mother decreases, the proportion of students with low academic performance increases, especially in Mathematics. Although this variable was not statistically significant at the time of regression analysis.

On the other hand, having books at home exhibits a similar behavior, being significant in both the bivariate and multivariate contexts. Having a sufficient number of books at home is a protective element against low school performance, both for mathematics $[\operatorname{EXP}(\beta)=0.66$; $\mathrm{P}$ $<0.01]$ and for Language $[\operatorname{EXP}(\beta)=0.68 ; \mathrm{P}<0.01]$.

Material conditions of existence shape the educational quality of the family environment and its capacity to influence the educational achievement of the children. The availability of cultural and symbolic artifacts reinforces the educational role of the parents, allowing the development of innovative and stimulating educational experiences at home. The greater presence of books, for example, would install reading habits, linguistic or vocabulary dominance and reading comprehension. This association has been found in several international studies such as PISA, TIMSS and PIRLS. Competencies are reinforced by parents with a higher level of education. The parental educational level not only influences the variety and relevance of cultural material at home, but also determines the type of relationship established with it (Rodríguez \& Muñoz, 2016).

\section{Conclusions}

The school, as a formal institution, is responsible for enabling an environment where students, especially the most vulnerable, are able to enhance their skills and abilities in the different areas of the school curriculum. However, the Education Quality Measurement System (SIMCE) in Chile demonstrates poor and segmented levels of achievement, both in the traditional learning sectors of language and mathematics and in the emerging ICT area.

In the language sector, one out of every two students presents serious difficulties in reading and understanding different types of texts. In mathematics similar results are observed where students present little mastery of arithmetic, algebra and geometry. The results of the ICT test do not differ in this regard. One in every two students demonstrates a functional and rudimentary management of the technologies, with a marginal use in the educational context.

The scores obtained in the standardized tests of Mathematics, Language and ICT, are conditioned by the students' family socio-economic segment. As the incomes scale descends the proportion of students with poor performance in the tests increases. This is an expression of the difficulty the school has to install quality learning and compensate for the deficiencies derived from the environment.

It is observed that educational competencies in the ICT test are related to school performance in the curricular areas of Mathematics and Language showing high and significant correlations. However, these would not be sufficient determinant. Rather the family social and cultural capital is the main structure of performance in the various tests applied.

The analyzed Multivariate Models report that, along with technological profile variables, socio-family attributes would have an impact on educational achievement. The demonstrated level of ICT competencies for learning and the technological equipment influence 
the probability of exhibiting poor school performance, both in Mathematics and Language, as well as the more precarious socio-cultural profile. The family socioeconomic group and having books at home are of special relevance in this matter.

ICTs have the potential to improve the quality and relevance of educational processes, but their real impact will depend on the technological competencies installed in the agents and the pedagogical intentionality that is systematically derived from it. Along with the use of communicative leisure, a less rudimentary technological appropriation and educational function is required, a particularly relevant challenge in the most vulnerable contexts.

\title{
Acknowledgement
}

This research was funded by the Universidad del Bío-Bío.

\author{
Declaration of interest \\ Conflicts of interest: none.
}

\section{References}

Aguirre, M., Castro, M., \& Adasme, A. (2009). Factores que inciden en el rendimiento escolar en Chile [Factors that affect school performance in Chile]. Talca: CEOC.

Arnold, D., \& Doctoroff, G. (2003). The early education of socioeconomically disadvantaged children. Annual Review of Psychology, 54, 517-545.

Belo, R., Ferreira, P., \& Telang, R. (2010). The effects of broadband in schools: Evidence from Portugal. SSRN, 1-38.

Brunner, J., \& Elacqua, G. (2005). Factores que inciden en una educación efectiva. Evidencia internacional [Factors that affect an effective education. International evidence]. Santiago: Universidad Adolfo Ibañez.

Bus, A., Van Ijzendoorn, M., \& Pellegrini, A. (1995). Joint book reading makes for success in learning to read: A meta-analysis on intergenerational transmission of literacy. Review of Educational Research, 65(1), 1-21.

Cerón, F., \& Lara, M. (2011). Factores asociados con el rendimiento escolar [Factors associated with school performance]. Santiago: Ministerio de Educación.

Claro, M. (2010). Impacto de las TIC en los aprendizajes de los estudiantes: Estado del arte [Impact of ICT on student learning: State of the art]. Santiago de Chile: Cepal.

Condie, R., Munro, B., Seagraves, L., \& Kenesson, S. (2007). The impact of ICT in schools - a landscape review. Milburn: Becta Research.

Cox, M. (2003). ICT and attainment: A review of the research literature. Conventry: Becta.

Cristia, J., Ibarraran, P., Cueto, S., Santiago, A., \& Severin, E. (2012). Technology and child development: Evidence from the "One laptop per child" program. IDB Working Paper, 1-43.

Enlaces. (2013). SIMCE TIC informe de resultados [SIMCE TIC results report]. Santiago: Ministerio de Educación.

Formichella, M., Alderete, M., \& Meglio, G. (2009). El acceso a las TIC en el hogar como determinante del rendimiento educativo en el nivel medio: un análisis para Argentina [Access to ICT in the 
Garcés \& Soto - School Performance and Technology: The Importance of ICT ...

home as a determinant of educational performance at the middle level: an analysis for Argentina]. Buenos Aires: CONICET.

Gisbert, M., \& Esteve, F. (2011). Digital Learners: La competencia digital de los estudiantes universitarios [Digital Learners: Digital competence of university students]. La Cuestión Universitaria (7), 48-59.

Gómez, L., \& Macedo, C. (2010). Importancia de las TIC en la educación básica regular [Importance of ICT in regular basic education]. Santiago: Educrea.

Hargittai, E. (2010). Digital na(t)ives? Variation in Internet skills and uses among members of the "net generation". Sociological Inquiry, 8o(1), 92-113.

Hollingworth, S., Mansaray, A., Allen, K., \& Rose, A. (2011). Parents' perspectives on technology and children's learning in the home: social class and the role of the habitus. Journal of Computer Assisted Learning, 27(4), 347-360.

IEA. (2008). International civic and citizenship education study. Assessment framework. Amsterdam: Education.

Jackson, L., von Eye, A., Biocca, F., Barbatsis, G., Zhao, Y., \& Fitzgerald, H. (2006). Does home internet use influence the academic performance of low-income children? Chicago: Developmental Psychology.

Jackson, L., von Eye, A., Witt, E., Zhao, Y., \& Fitzgerald, H. (2011). A longitudinal study of the effects of Internet use and videogame playing on academic performance and the roles of gender, race and income in these relationships. El Sevier, 27(1), 228-239.

Lozano, A. (2003). Factores personales, familiares y académicos que afectan al fracaso escolar en la educación secundaria [Personal, family and academic factors that affect school failure in secondary education]. Revista Electrónica de Investigación Psicoeducativa $y$ Psicopedagógica, 1(1), 43-66.

Magnuson, K. (2007). Maternal education and children's academic achievement during middle childhood. Developmental Psychology, 43(6), 1497-1512.

Marks, G., Cresswell, J., \& Ainley, J. (2006). Explaining socioeconomic inequalities in student achievement: The role of home and school factors. Educational research and Evaluation, 12(2), 105-128.

Matear, A. (2007). Equity in education in Chile: The tensions between policy and practice. International Journal of Educational Development, 27(1), 101-113.

McFarlane, A., Sparrowhawk, A., \& Heald, Y. (2002). Report on the educational use of games. California: TEEM.

Montero, R., \& Nahuelpán, V. (2010). El uso del computador y el impacto en la prueba SIMCE [Use of computer and impact on the SIMCE test]. Santiago: Universidad Diego Portales.

Mora, A. (2010). Los resultados SIMCE y las desigualdades del sistema educativo chileno [The SIMCE results and inequalities of the Chilean educational system]. Santiago: Ministerio de Educación.

Morrissey, J. (2007). El uso de TIC en la enseñanza y el aprendizaje. Cuestiones y desafíos [Use of ICT in teaching and learning. Issues and challenges]. Lima: Corn.

Navarro, E. (2003). El rendimiento académico: Concepto, investigación y desarrollo [Academic performance: Concept, research and development]. REICE, 1(2), 1-16.

OCDE. (2010). Results: Learning to learn. Student engagement, strategies and practices, Volume III. Santiago: OCDE.

Pedró, F. (2006). Un diagnóstico de la situación del profesorado en España desde una perspectiva comparativa [A diagnosis of the situation of teachers in Spain from a comparative perspective]. Revista de Educación (340), 243-264. 
Piacente, T., \& Tittarelli, A. (2009). La lectura de cuentos dialógica y las características de la interacción según estrato [The reading of dialogical stories and the characteristics of the interaction according to stratum]. Evaluar, 9, 1-18.

Rodríguez, C., \& Muñoz, J. (2016). Calidad educativa del ambiente familiar y escolaridad materna [Educational quality of the family environment and maternal education]. Paradigma, 37(1), 76-98.

Rodríguez, E. (2014). La influencia de los factores familiares en el rendimiento académico [Influence of family factors on academic performance]. Valladolid: Universidad de Valladolid.

Román, M., \& Murillo, F. (2014). Disponibilidad y uso de TIC en escuelas latinoamericanas: Incidencia en el rendimiento escolar [Availability and use of ICT in Latin American schools: Effects on school performance]. Educação e Pesquisa, 40(4), 869-895.

Santín, D. (2003). Influencia de los factores socioeconómicos en el rendimiento escolar internacional: Hacia la igualdad de oportunidades educativas [Influence of socioeconomic factors on international school performance: Towards equal educational opportunities]. Barcelona: UCM.

Schofield, L., Demont, C., \& Webber, S. (2005). Parents, ICTs, and children's prospects for success: Interviews along the digital "Access Rainbow". Critical Studies in Media Communication, 22(5), 409-426.

Schütz, G., Ursprung, H., \& Wöbman, L. (2008). Education policy and equality of opportunity. Kiklos, 61(2), 279-308.

Spelke, E. (2005). Sex differences in intrinsic aptitude for mathematics and science?: A critical review. American Psychologist, 6o(9), 950-958.

Spiezia, V. (2011). Does computer use increase educational achievements? Student-level evidence from PISA. OECD Economic Studies, 1(7), 1-22.

Tedesco, J. (2000). Educar en la sociedad del conocimiento [Educate in the knowledge society]. Fondo de Cultura Económica, 11-70.

Tejedor, F., \& García-Valcárcel, A. (2006). Competencias de los profesores para el uso de las TIC en la enseñanza. Análisis de sus conocimientos y actitudes [Teachers' competences for the use of ICT in teaching. Analysis of your knowledge and attitudes]. Revista Española de Pedagogía, LXIV (233), 21-44.

Torres, J., \& Padilla, A. (2015). Las tecnologías de la información y comunicación y su efecto en el rendimiento académico de los estudiantes en las escuelas secundarias del departamento de Córdoba - Colombia [Information and communication technologies and their effect on academic performance of students in secondary schools in the department of Córdoba Colombia]. Revista Ingeniería al Día, 15-23.

Trucano, M. (2005). Knowledge Maps: ICT in Education. Washington: World Bank.

Woessmann, L., \& Fuchs, T. (2004). Computers and student learning: Bivariate and multivariate evidence on the availability and use of computers at home and at school. CESifo Working Paper, 1-34. 
Garcés \& Soto - School Performance and Technology: The Importance of ICT ...

C O A S 